\title{
Veranderen: een meervoudig perspectief
}

\section{Verschillende manieren van denken over veranderen ${ }^{1}$}

\author{
L. de Caluwé • L. de Caluwé
}

Samenvatting In dit artikel worden vijf zienswijzen op veranderen beschreven. Deze zienswijzen zijn onderling strijdig maar beschrijven en verklaren elk een deel van de werkelijkheid. Het zijn geeldrukdenken: een socio-politieke zienswijze; blauwdrukdenken: een rationele, empirische zienswijze; rooddrukdenken: een mensgerichte, relationele zienswijze; groendrukdenken: een leergeoriënteerde benadering en witdrukdenken: een visie van zelfsturing en zelforganisatie. Met deze (meta-)theorie kan men organisaties beschrijven en diagnosticeren: hoe zien ze eruit en hoe kan ik ze begrijpen? Men kan er veranderingsprocessen mee ontwerpen: hoe kan ik met deze verandering in deze context omgaan? Men kan zich bewust worden van de eigen voorkeuren en allergieën: waarom ben ik altijd geneigd tot bepaalde benaderingen en zie ik andere over het hoofd? En men kan ermee kijken naar communicatie: waarom klikt het in de ene situatie en waarom stagneert en conflicteert het in de andere? (Caluwé L de. Veranderen: een meervoudig perspectief. Verschillende manieren van denken over veranderen. Tijdschrift voor Medisch Onderwijs 2007;26(6):265-271.)

\section{Inleiding}

Rondom het woord 'veranderen' bestaat nogal wat begripsverwarring. Als je even onder de oppervlakte van dat woord kijkt, kom je heel verschillende betekenissen en waarden tegen. Er worden aanpakken, benaderingen en strategieën gesuggereerd waarin werelden van verschil liggen tussen de achterliggende overtuigingen,

L. de Caluwé $(\bowtie)$

Prof. dr. L. de Caluwé is hoogleraar advieskunde, Vrije

Universiteit Amsterdam. Correspondentieadres: veronderstellingen en opvattingen. In dit artikel worden de vijf families van denken over veranderen beschreven. Tezamen vormen deze families van theorieën een (meta-) theorie, die vervolgens vier toepassingsgebieden kent. Die worden ook beschreven.

\section{Vijf kleurendrukken}

Aan de vijf manieren van denken over veranderen zijn kleurenlabels gegeven. Dat is een goede keus geweest: deze kleurenlabels zijn heel populair geworden. Maar in zekere zin zijn de kleuren het minst belangrijke aan het denken over veranderen: het gaat om de onderliggende contrasterende set van overtuigingen over veranderen (ook wel geloofssystemen genoemd) en niet over verfpigmenten of lichtgolflengtes.

De lettergreep 'druk' verwijst naar het streven van veranderaars om toch min of meer planmatig te werk te gaan, ook al laat je alles - doelbewust - op zijn beloop. Je wilt immers iets kunnen voorspellen, beredeneren of beïnvloeden. Dat gaat per kleur overigens zeer verschillend.

\section{Geeldrukdenken}

Geeldrukdenken is gebaseerd op socio-politieke opvattingen over organiseren, sturen en veranderen, waarbij belangen, conflicten, macht en posities een belangrijke rol spelen. Het veronderstelt dat veranderingen niet tot stand komen als ze niet gesteund, gelegitimeerd of

\footnotetext{
${ }^{1}$ Dit op uitnodiging geschreven artikel is gebaseerd op een voordracht op het NVMO-congres in 2006 en is een samenvatting van een deel van het boek "Leren veranderen".
} 
gesanctioneerd worden door een coalitie van machthebbers, opinieleiders of krachtige persoonlijkheden. Draagvlak creëren, belangen bundelen, win-win situaties maken zijn favoriete manieren van doen.

Geeldrukdenkers zijn vaak te herkennen aan het volgende spraakgebruik: achterbannen, comités, mandaten, pettenprobleem, gezichtsverlies, agenda's, en dergelijke. Ze geloven dat iedereen handelt uit eigenbelang, dat er altijd verborgen agenda's zijn en dat het niet zozeer uitmaakt wat iemand zegt, maar wie het zegt. En niet om wat je kent, maar wie je kent. De machtigen moeten zich achter een bepaalde verandering scharen (een compromis waarschijnlijk). Zo niet, dan lijdt de verandering schipbreuk.

\section{Blauwdrukdenken}

Blauwdrukdenken is gebaseerd op het wetenschappelijkempirisch en rationeel optimaliseren van processen. Hierbij worden de deugden van efficiënt organiseren, van gedetailleerde specificaties, planning en controle onderstreept. De wijze van benadering is rationeel (planning) en empirisch (kengetallen). Eerst denken (definiëren en ontwerpen) en daarna doen (implementeren of uitrollen) is het adagium. Het resultaat wordt van te voren bepaald, evenals de weg ernaar toe: van A naar B.

Favoriete denkmodellen zijn stappenplannen, handboeken en richtlijnen. Meten is weten; gokken is dokken en gissen is missen. Afspraak is afspraak; geen geld, geen Zwitsers. Het geloof is dat de wereld maakbaar, beheersbaar, planbaar en kenbaar is. Wat niet meetbaar is, doet er eigenlijk niet toe. De boeken, plannen en presentaties zien er hier dan ook altijd erg zakelijk, consistent en transparant uit. Er is een buitengewoon heilig geloof in de alwetendheid van experts en de empirische wetenschappen: is dat bewezen of aangetoond? En wat is HET beste? Dat meerdere dingen goed zouden zijn, is onbestaanbaar.

\section{Rooddrukdenken}

Rooddrukdenken vindt zijn grondslag in de aandacht voor 'human relations'. Hoe kun je mensen motiveren? Wat is effectieve menselijke communicatie? Hoe kun je het beste uit mensen halen en hoe kun je mensen ontwikkelen?

Favoriete manier van doen is, naast het belonen en prikkelen van mensen, ook het bevorderen van een 'wijgevoel': cohesie en binding van mensen met de organisatie. Mensen willen ergens bijhoren, willen een gevoel van saamhorigheid hebben. Dat is de reden waarom goede communicatie, goed samenwerken en teambuilding worden gezien als nastrevenswaardige deugden. Het geloof is dat veranderingen alleen kunnen plaatsvinden in persoonlijke, open en respectvolle conversaties. En daarbij moet steun, erkenning, perspectief en respect aan mensen gegeven worden. Een tevreden medewerker is een productieve medewerker. De verandering moet aangenaam, leuk en aantrekkelijk zijn. Mensen moeten zich ernaar toe willen bewegen. Het woord 'moeten' of 'dienen' (dat veel gebruikt wordt bij de gele en blauwe benadering) wordt hier juist weggelaten. "Wij zetten er samen de schouders onder omdat we dat willen en met zijn allen nodig vinden".

\section{Groendrukdenken}

Groendrukdenken is gebaseerd op het gedachtegoed van 'action learning', organisatie- ontwikkeling en de lerende organisatie. Veranderen en leren betekenen zo ongeveer hetzelfde: als je leert, verander je; en als je verandert, leer je. Het gaat dan om het eigen maken van nieuwe vermogens, om het aanpassen aan veranderde omstandigheden of het zich bewust worden van de eigen manieren van doen en kijken. Als mensen 'bewust onbekwaam' worden, zien ze wat ze nog niet weten of kunnen en zijn ze gemotiveerd om daarin te investeren en daaraan te werken. Dat kan door het hanteren van twee veranderingsbenaderingen: spiegels en vensters. Spiegels staan voor 'het goed naar jezelf kijken', bij voorkeur door de ogen van anderen (door feedback, coaching, intervisie). Vensters staan voor 'nieuwe vergezichten' zodat je kunt zien dat dingen heel anders kunnen gaan (goede voorbeelden, rolmodellen, stages, bezoeken brengen). Leren en veranderen doe je in het werk en samen met anderen. Reflectie en tijdelijk vertragen (stil staan bij wat er gebeurt of gebeurd is) zijn altijd nodig en vormen het essentiële onderdeel. Hiervoor is veiligheid nodig, zodat mensen willen openstaan, en dat ook durven, voor ideeën of inzichten van anderen. Je mag en moet van fouten leren. Alles kan immers altijd beter.

\section{Witdrukdenken}

Witdrukdenken is ontstaan als een reactie op het deterministische, mechanistische en lineaire wereldbeeld dat is afgeleid van Newton. De chaostheorie draait om levende complexe systemen met een beperkte voorspelbaarheid. Zelforganisatie, betekenisgeving en wilsvorming zijn centrale begrippen. Verandering vindt autonoom plaats: alles stroomt altijd. Beïnvloeding is slechts beperkt mogelijk.

Mensen komen in actie op grond van hun drijfveren en ze stellen zichzelf open voor verandering. Niet omdat het moet of zo hoort, maar omdat men het wil, er klaar voor is en de tijd rijp is. Interventies waarin men gelooft zijn gebaseerd op intensieve interactie, dialoog en 
betekenisgeving. Het gaat om het begrijpen en leren omgaan met dilemma's en paradoxen, met patronen, complexiteit, onzekerheid en met onvoorspelbaarheid. Daardoor komt het weten van binnenuit: zo zie ik het; zo wil ik het. Witdrukdenkers zijn zelfbewuste actoren (daders) die weten wat ze willen. Ze zijn nauwelijks te beïnvloeden. Tenzij ze dat zelf willen natuurlijk. Ze zijn creatief, innovatief, maar ook grillig en eigenwijs.

\section{Gelijkwaardige manieren van denken}

De kleuren zijn gelijkwaardig. De ene is niet superieur aan de andere. Ze kunnen namelijk alle vijf zeer effectief zijn, gegeven bepaalde veranderingen en bepaalde contexten. Ze hebben bovendien allemaal fraaie idealen. En als je kundig en functioneel met een kleur aan de slag gaat kun je dingen bereiken. Maar de kleuren kunnen ook disfunctioneel zijn. Om wat voorbeelden te noemen: een structuur bouwen, moet je blauw aanpakken; het veranderen van een bedrijfscultuur: groen; een goed psychologisch klimaat maken: rood; innoveren: wit; draagvlak en besluiten: geel. Dat betekent ook dat de kleuren heel verschillende definities hebben wat betreft succes of effectiviteit. Wat volgens de gedachtegang van een bepaalde kleuraanhanger een succes is, is in de ogen van een andere juist geen succes. Met andere woorden: er is geen gemeenschappelijk kader waarmee verschillende begrippenapparaten met elkaar gemeten of vergeleken kunnen worden. Gele veranderaars waarderen bijvoorbeeld dat men elkaar heeft kunnen vinden in een compromis. Rode veranderaars hechten aan een goede sfeer waarin mensen zich gerespecteerd voelen. Beide (succes-)criteria zijn voor blauwdrukdenkers hooguit bijzaken als het gaat om succes: 'wat is klaar', dat is wat zij belangrijk vinden.

Veronderstellingen achter de vijf manieren van denken.

\begin{tabular}{|c|c|c|}
\hline Kleur & & Dingen/mensen zullen veranderen als je..... \\
\hline \multirow[t]{6}{*}{ Geeldruk } & $\cdot$ & belangen bij elkaar kunt brengen \\
\hline & • & ze kunt overhalen tot het innemen van (bepaalde) standpunten/meningen \\
\hline & • & win-win situaties kunt creëren/coalities vormen \\
\hline & • & de voordelen kunt laten zien van bepaalde opvattingen (macht, status, invloed) \\
\hline & • & de neuzen kunt richten van de mensen die 'er toe doen' \\
\hline & • & ze in een onderhandelingsproces kan krijgen \\
\hline \multirow[t]{6}{*}{ Blauwdruk } & • & van tevoren een duidelijk resultaat/doel formuleert \\
\hline & • & een goed stappenplan maakt van A naar B \\
\hline & • & keuzes baseert op inhoudelijke expertise en empirische bewijzen \\
\hline & • & de stappen goed volgt en op basis daarvan bijstuurt \\
\hline & • & alles zoveel mogelijk stabiel houdt en beheerst \\
\hline & • & de omgevingscomplexiteit zoveel mogelijk reduceert \\
\hline \multirow[t]{5}{*}{ Rooddruk } & • & ze op de juiste manier prikkelt en motiveert \\
\hline & • & het voor mensen aangenaam maakt (sociale settings) \\
\hline & • & geavanceerde HRM-instrumenten inzet voor belonen, motiveren, promoveren, status \\
\hline & • & ze aandacht, respect, vertrouwen en erkenning geeft \\
\hline & • & ze iets teruggeeft voor wat zij jou geven \\
\hline \multirow[t]{5}{*}{ Groendruk } & • & ze bewust maakt van nieuwe zienswijzen/eigen tekortkomingen (bewust onbekwaam) \\
\hline & • & ze kunt motiveren om nieuwe dingen te zien/te leren/te kunnen \\
\hline & • & ze in staat stelt eigen leerdoelen te stellen en het eigen leerproces mee vorm te geven \\
\hline & • & geschikte (gezamenlijke) leersituaties kunt creëren \\
\hline & • & ze helpt groeien \\
\hline \multirow[t]{6}{*}{ Witdruk } & • & aansluit op de 'natuurlijke weg', de 'roeping' van mensen zelf \\
\hline & • & ruimte biedt voor de eigen energie, inspiratie en kracht van mensen \\
\hline & • & dynamiek/complexiteit wilt duiden en kunt zien waar 'de tijd rijp voor is' \\
\hline & • & eventuele blokkades wegneemt en conflicten optimaliseert \\
\hline & • & betekenis toevoegt aan de processen waar mensen in zitten \\
\hline & - & symbolen en rituelen gebruikt \\
\hline
\end{tabular}




\section{Vier toepassingsgebieden}

Wat kun je nu met dit inzicht in deze vijf manieren van denken? In de loop der jaren zijn vier toepassingsgebieden ontwikkeld voor de kleurentheorie:

1. het kijken naar organisaties

2. het aanpakken van verandering

3 . het opereren als veranderaar

4. het communiceren over veranderingen.

\section{Kijken naar organisaties}

In elke organisatie, en zelfs in elke afdeling, zijn de kleuren zichtbaar: in werkprocessen, in wijze van leiding geven, in wijze van samenwerking, in veranderaanpakken, in gewenste uitkomsten of in idealen. De kleuren kunnen een krachtig hulpmiddel zijn bij het diagnosticeren van delen van organisaties of van hele organisaties.

De kleuren verschaffen de taal om bijvoorbeeld te zeggen: "De dominante spelregels hier zijn vooral groen", óf: "Ik hoor hier nu nooit eens rode oplossingen", óf: "De managementstijl is erg blauw". Als een veranderaar zich bewust is van veranderkleuren, wordt hij gestimuleerd om meervoudig te kijken. Hij kan zich nog eens afvragen of het vanuit een andere kleur toch weer niet anders in elkaar zit. Hij zet dan steeds een andere bril op.

Sommige organisaties hebben van nature dominante kleuren. In door logistieke processen gevormde organisaties is dat vaak dominant blauw; bij - echte - professionals: veel groen; bij het openbaar bestuur: het onvermijdelijke geel. Eén van de grootste problemen is echter eenzijdigheid: té lang, té veel van alleen bepaalde kleuren, en afwezigheid van andere kleuren. Dat wordt dan in alles bevestigd: andersdenkende nieuwelingen of adviseurs worden geweerd. "Die begrijpen ons niet", zeggen ze dan.

Organisaties zouden juist meerkleurigheid moeten zoeken: de ideale, op lange termijn gerichte, gezonde organisatie heeft alle kleuren in een dynamisch evenwicht. Maar daarmee haal je ook alle tegenstellingen, conflicten en paradoxen tussen de kleuren binnen. Als organisatie moet je dan leren om te gaan met die concurrerende werkelijkheden, die elk van de kleuren met zich meebrengt. Dat vermogen moet collectief zijn: men moet de dilemma's zien, ze begrijpen en er iets mee kunnen. Als je er niet mee kunt omgaan worden de dilemma's immers conflicten en tegenstellingen die leiden tot stagnatie en miscommunicatie. Er wordt dan gezegd: "het lijkt wel alsof hij van een andere planeet komt", "dat gaat echt niet werken", "zij begrijpen er helemaal niets van". Met als gevolg dat de communicatie juist stokt in plaats van productief wordt.
Aanpakken van verandering

Alle kleuren hebben hun sterke kanten. Dat betekent dat sommige aanpakken beter passen bij bepaalde typen veranderingen. Een gebouw neerzetten vergt een blauwe aanpak. Dat geldt ook voor het maken van een organisatiestructuur of een opleidingsplan. Als je echter een goede sfeer wilt maken, heb je meer aan een rode aanpak. Wil je mensen leren klantgericht te kijken en te handelen, dan ligt een leer-georiënteerde benadering meer voor de hand.

De wijze van aanpakken past ook vaak bij een bepaald type mensen. Mensen grijpen naar hun favoriete benaderingswijze, ongeacht het type verandering of de context waarin die plaatsvindt. Soms zal in een bepaalde context alleen bepaalde aanpakken geaccepteerd worden, omdat men de alternatieve benaderingen niet ziet of die zal afwijzen.

Het komt ook voor dat er een combinatie nodig is. In één veranderingstraject kunnen dan verschillende kleuren voorkomen: onderhandelen over het benodigde budget (geel); een plan maken (blauw), communiceren met de doelgroep (rood), coachen van anderen (groen) en ruimte scheppen (wit). Eén kleur moet echter de hoofdbenadering zijn, omdat anders in de (meta-)communicatie geen heldere boodschap over kan komen.

\section{Opereren als veranderaar}

Veranderaars hebben net als alle andere mensen dominant gedrag. Niet iedereen heeft alles in huis. Je bent sterk in bepaalde kleuren, zwak in andere. Je hebt voorkeuren en allergieën. Maar het is wel mogelijk, gegeven een dominante kleur, om in andere kleuren te leren kijken, ze te begrijpen en daarin eenvoudige interventies te doen. Wel is het zo dat het nagenoeg onmogelijk is om in andere kleuren dan jouw favoriete kleuren te interveniëren in de daarbij behorende stijl, achterliggende inzichten en geloofwaardigheid. Het advies is om jezelf op dit punt goed te (leren) kennen en om goed te weten wanneer hetgeen gevraagd wordt niet (meer) bij jouw competenties en sterktes past. Of juist wel natuurlijk, want dan zit je juist in je kracht. Er zijn twee stromingen. De aanhangers van de ene stroom menen dat je vooral die competenties waar je niet goed in bent moet ontwikkelen. De anderen zeggen dat je juist die competenties waar je goed in bent moet ontwikkelen. We sluiten ons aan bij de tweede stroming.

\section{Communiceren over veranderingen}

Het is heerlijk als je aan een half woord genoeg hebt, als een collega goed bij je aansluit, als je op een zelfde manier 
naar de wereld kijkt, als 'het klikt'. Je kunt snel aan de slag, zit op één lijn en je hebt hetzelfde beeld voor ogen. Maar juist deze knusheid kan eenzijdigheid versterken. Het alternatief is je eigen onzekerheid organiseren door mensen erbij te betrekken die juist anders kijken, denken en doen. Dat levert op zich weer mogelijke nadelen op: spraakverwarring, stroefheid, conflicten en defensief gedrag. De kunst is om met andersdenkenden om te gaan als een uitdaging en als een vorm van kaderverruiming.

De kleurentheorie is een niet-bedreigende manier om tussen mensen verschillende overtuigingen en geloofssystemen op tafel te krijgen en bespreekbaar te maken. De theorie depersonifieert. Het is niet zo dat Jan niet deugt: Jan komt van de blauwe planeet, daar denken ze zo en dat is soms wel handig. Je kunt dat vreemd vinden en moeilijk te begrijpen omdat het niet bij jou past. Maar je kunt er ook mild over worden en het leren accepteren. Een mooi begrip voor dat proces is: 'de plek der moeite': het kost moeite om andere overtuigingen te begrijpen, ook die van jezelf. En het is tegelijk de moeite waard om deze plek op te zoeken en er tijd aan te besteden om het te leren begrijpen.

\section{Conclusie}

We hebben, ons inziens, met deze kleurentheorie een intelligente vereenvoudiging van de werkelijkheid gemaakt. De theorie probeert niet de werkelijkheid te beschrijven in termen van: het is waar of het is onwaar. Wel maakt theorie de werkelijkheid hanteerbaar door middel van nieuwe taal, nieuwe concepten en nieuwe labels. Met die nieuwe taal en labels is de werkelijkheid beter te doorgronden en de complexiteit ervan beter te doorzien. Het biedt de mogelijkheid onder de oppervlakte te kijken en te zien en te begrijpen dat de onderliggende waarden en overtuigingen een belangrijke rol spelen. Zichtbaar wordt waarom veranderingen soms plaatsvinden, soms stagneren, soms tot conflicten leiden, soms onbedoeld verlopen en soms strijdige uitkomsten opleveren. Maar vooral helpt het veranderaars om beter en meer betekenisvol met elkaar over veranderen te praten. Want ook veranderaars zelf hebben hun voorkeuren, allergieën, overtuigingen. Je kunt niet kleurloos praten en denken. Jezelf bewust worden van die voorkeuren en afkeuren is een voorwaarde voor een betekenisvolle dialoog.

De concepten van de kleuren laten zich toepassen op macroprocessen van verandering: in de samenleving en in organisaties. Maar ook op microsituaties: in een gesprek tussen twee individuen. Blijkbaar zijn ze heel generiek. Belangenconflict: geen gemeld.

Financiële ondersteuning: geen gemeld.

\section{Summary}

Five different, contradictory ways of thinking about change are the topic of this article. Each of these five mindsets focuses on and explains a part of reality. We use different colours to characterise these mindsets. Yellowprint thinking is a socio-political way of thinking; blueprint thinking is rational and empirical; redprint thinking is a relational, peopleoriented way of thinking; greenprint thinking is learning oriented; and whiteprint thinking focuses on self-direction and self-organisation.

This (meta)-theory of change can be used to describe an organisation and identify its dominant characteristics: what does this organisation look like and how can I understand it? The colour scheme can also be helpful in designing change processes: how should I address change processes in this specific context? At a personal level, the scheme can foster people's awareness of their own preferences and allergies: why do I tend to always favour certain approaches while ignoring others? And it offers a perspective on communication: why are things going smoothly in one setting and why are stagnation and conflict rife in another one? (Caluwé L de. Multiple perspectives on change; different ways of thinking about change. Dutch Journal of Medical Education 2007;26(6):265-271.)

\section{Literatuur}

Caluwé L de, Vermaak H. Leren Veranderen. Een handboek voor de veranderkundige. Tweede geheel herziene editie. Deventer: Kluwer; 2006. 